\title{
Do GAAP And IFRS Differ In Collectiblity Judgments Related To Revenue Recognition?
}

\author{
Ning Du, DePaul University, USA
}

R. Mark Alford, DePaul University, USA

Patricia L. Smith, DePaul University, USA

\begin{abstract}
The goal of this study is to examine whether financial statement preparers may interpret the collectibility threshold differently given the differences in the prior definitions of "probable" in IFRS and GAAP. We conducted an experiment where participants were provided with either the IFRS or GAAP definition of "probable" and then asked to evaluate five short revenue recognition scenarios. We find that their judgments regarding collectibility of consideration did not differ across the IFRS or GAAP conditions. This study contributes to the prior accounting literature on interpreting vague verbal probability terms and expands this line of work to the arena of revenue recognition. Our results also provide insight for standard setter and policy makers in their efforts to achieve true convergence in accounting standards.
\end{abstract}

Keywords: ASC 606 Revenue from Contracts with Customers; Collectibility of Consideration; GAAP Versus IFRS Interpretation of "Probable"

\section{INTRODUCTION}

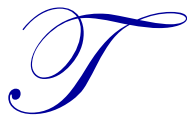

he Financial Accounting Standards Board (FASB) and the International Accounting Standards Boards (IASB) have recognized that the authoritative literature related to revenue recognition had significant inconsistencies across entities. In order to improve the usefulness of financial statement information, the FASB and IASB, in May 2014, issued converged guidance on recognizing revenue from contracts with customers. The new guidance (GAAP's Accounting Standards Update (ASU) 2014-09, (Topic 606) and IFRS 15 both entitled Revenue from Contacts with Customers supersedes all previous issued guidance. The fully converged standard for U.S. generally accepted accounting principles (GAAP) and the International Financial Reporting Standards (IFRS) provides consistent guidance on how revenue is to be recognized and reported. One of the primary goals of the two standard setting bodies in issuing a fully converged standard was to improve comparability of recognizing and reporting revenue across entities, industries, jurisdictions and capital markets. This enhanced comparability will require consistent interpretation of the converged guidance in order to ensure the desired outcome.

Revenue is a vital metric for users of financial statements and is used to assess a company's financial performance as well as its prospects for the future. According to ASU 2014-09 (Topic 606 in the FASB Accounting Standards Codification), "The core principle of the guidance is that an entity shall recognize revenue to depict the transfer of promised goods or services to customers in an amount that reflects the consideration to which the entity expects to be entitled in exchange for those goods or services." The new guidance found in ASU 2014-09 will also result in enhanced disclosures about revenue, provide guidance for transactions that were not previously addressed comprehensively (for example, service revenue and contract modifications) and improve guidance for multiple-element arrangements. Following the core principle of the guidance, an entity will recognize revenue by applying a five-step model. The gateway to the model is the first of the five steps: Identify the contract(s) with a customer. Subparagraph 606-10-251e of the ASC cited above indicates that a contract does not exist (Step 1) for purposes of the revenue recognition model unless "It is probable that the entity will collect the consideration to which it is entitled in exchange for the 
goods or services that will be transferred to the customer." [emphasis added] This determination is based upon an entity's evaluation of "the customer's ability and intention to pay that amount of consideration when it is due." Because Step 1 is the gateway to the new revenue recognition model, no revenue can be recognized when an entity concludes that collectibility of consideration is not probable.

In spite of the efforts for a converged revenue recognition standard, the use of verbal probability terms such as "probable" is problematic. Verbal probability terms are vague and subject to varying interpretation. To illustrate, IFRS and GAAP have provided different definitions of this term. Section 450-20-20 of the Codification (FASB Statement No. 5, Accounting for Contingencies) defines the term "probable" as, "The future event or events are likely to occur". Paragraph 37 of IAS 37, Provisions, Contingent Liabilities and Contingent Assets, defines the term "probable" as, "the event is more likely than not to occur, i.e. the probability that the event will occur is greater that the probability that it will not". Thus, subtle differences still remain between the GAAP and IFRS definitions of "probable". As pointed out by IASB member Stephen Cooper during the joint meeting: "We're not really coming together, are we, because we're saying the same word, but we're meaning something different". (http:// www. Journal of accountancy. $\mathrm{com} /$ news/2013). It is certainly possible, if not likely, that differences in interpreting "probable" may lead to different patterns of revenue recognition.

The goal of this study is to examine whether financial statement preparers may interpret the collectibilty threshold differently given the differences in the prior definitions of "probable" in IFRS and GAAP. We conducted an experiment where participants were provided with either the IFRS or GAAP definition of "probable" and then asked to evaluate five short revenue recognition scenarios. We find that their judgments regarding collectibility of consideration did not differ across the IFRS or GAAP conditions. This study contributes to the prior accounting literature on interpreting vague verbal probability terms and expands this line of work to the arena of revenue recognition. Our results also provide insight for standard setter and policy makers in their efforts to achieve true convergence in accounting standards.

\section{LITERATURE REVIEW}

\subsection{Revenue Recognition}

As the most important financial reporting or top of the line item, revenue is used to assess a company's financial performance and prospects. However, the previous authoritative guidance found in IFRS and GAAP was not the same and often resulted in inconsistent accounting treatment for transactions that were economically similar. Furthermore, while revenue recognition requirements of IFRS lacked sufficient detail, the accounting requirements of US GAAP were considered to be overly prescriptive and even conflicting in certain areas. The current, fully converged requirements for the recognition of revenue found in ASU 2014-09 and IFRS 15 provide substantial enhancements to the quality and consistency of how revenue is reported while also improving comparability in the financial statements. As pointed out by Russell Golden, Chairman of the FASB: "The revenue recognition Standard represents a milestone in our efforts to improve and converge one of the most important areas of financial reporting. It will eliminate a major source of inconsistency in GAAP, which currently consists of numerous disparate, industry-specific pieces of revenue recognition guidance. The issuance of this Standard is a major first step, but it is not the end of the process."

The essence of both ASU 2014-09 and IFRS 15 is a five-step process that is based upon achieving the "core principle" of the authoritative guidance. This core principle, according to the FASB in ASU 2014-09 "is that an entity should recognize revenue to depict the transfer of promised goods or services to customers in an amount that reflects the consideration to which the entity expects to be entitled in exchange for those goods or services." IFRS makes the same comment related to the core principle. 
The five-step process referred to above includes the following:

Step 1: Identify the contract(s) with a customer.

Step 2: Identify the performance obligations in the contract.

Step 3: Determine the transaction price.

Step 4: Allocate the transaction price to the performance obligations in the contract.

Step 5: Recognize revenue when (or as) the entity satisfies a performance obligation." [FASB, ASU 2014$09,2]$.

The revenue recognition guidance found in ASU 2014-09 (embodied in Topic 606 of the ASC) and that in IFRS 15 is for all practical purposes, the same. More specifically, paragraph IN5 of IFRS 15 says, "Accordingly, the International Accounting Standards Board (IASB) and the US national standard-setter, the Financial Accounting Standards Board (FASB), initiated a joint project to clarify the principles for recognising revenue and to develop a common revenue standard for IFRS and US GAAP that would:

(a) remove inconsistencies and weaknesses in previous revenue requirements;

(b) provide a more robust framework for addressing revenue issues;

(c) improve comparability of revenue recognition practices across entities, industries, jurisdictions and capital markets; IFRS 15 IFRS Foundation A679

(d) provide more useful information to users of financial statements through improved disclosure requirements; and

(e) simplify the preparation of financial statements by reducing the number of requirements to which an entity must refer."

A similar statement is presented in the Summary of ASU 2014-09.

Subsequent to the issuance of ASU 2014-09 the FASB issued ASU 2015-14, Revenue from Contracts with Customers (Topic 606), Deferral of the Effective Date in August 2015. The effective date ASU 2014-09 was postponed for public companies one year "to annual reporting periods beginning after December 15, 2017, including interim reporting periods within that reporting period." ASU 2015-14 does allow early application but only "as of annual reporting periods beginning after December 15, 2016, including interim periods within that reporting period [the effective date of ASU 2014-09]." The effective date of ASU 2014-09 for public companies was specified as "annual reporting periods beginning after December 15, 2016, including interim periods within that reporting period." Early application of ASU 2014-09 was not permitted. The effective date of IFRS 15 is for "annual reporting periods beginning on or after 1 January 2017." IFRS 15 did allow early application but if early application did occur, this fact had to be disclosed.

\subsection{Verbal Probability Judgment}

Successful implementation of the new revenue standard hinges on the consistent application of the collectibilty threshold which contribute to the determination of the existence of a contract with a customer for purposes of the revenue recognition model (Step 1). Specifically, no revenue can be recognized when an entity concludes that collectibility of consideration is not probable. Thus, interpreting the term "probable" is critical in evaluating uncertainty and assessing the customer's ability and intention to pay the amount of this consideration when due. If different accountants interpret "probable" differently, they may reach different decisions about revenue recognition. However, interpreting verbal probabilities is not an easy task.

People rely on probability to describe uncertainty in daily life and communicate with others. Probability can be expressed numerically or verbally. Numeric probability is more precise than verbal probability, but people tend to prefer the use of verbal probability terms to communicate with others. For example, we may say "today it probably will rain" instead of "today has a $75 \%$ chance of raining". Compared to numerical probabilities, verbal probabilities include a wide range of values, and thus, they are more vague and imprecise. Because different people comprehend language differently, and thus, different people may attribute different numerical to a single phrase. A wide of range 
of values can accommodate disagreements among individuals and minimize problems with misinterpretation of numeric probabilities, but imprecision in values also causes differences and inconsistency in uncertain beliefs (Wallsten et al. 1993). Different people may have different interpretation of "probable", some may attribute a $70 \%$ numeric value and other may attribute $90 \% \%$ value. Different interpretations may lead to different decisions/actions. In the weather example, a person with a judgement of $70 \%$ may not bring an umbrella and eventually get soaked, while the person with a $90 \%$ judgment may decide to bring one and stay dry. Thus, it is important to understand how people interpret and represent the meaning of such ordinary language probability statements (Wallsten et al. 1993). Accounting standards also rely on verbal probabilities. Prior accounting researchers have found people assign different values to the same probability term and it is difficult for accountants and auditors to consistently interpret the verbal criteria (Du et al. 2011a, b, 2016).

Accounting standards often rely on verbal probabilities. Most commonly observed is the authoritative guidance as it applies to whether a loss contingency (in GAAP) or a provision (in IFRS) should be accrued. Accounting scholars have been interested in how experts, such as accountants and auditors, interpret these verbal terms and apply these terms in their profession. Many researchers have focused on SFAS 5, Accounting for Contingencies, in US GAAP and attempted to understand how individuals assign a numeric value in the $0 \%$ to $100 \%$ probability continuum to the terms related to loss contingencies used in the standard (e.g., probable, reasonably possible or remote) into different decision regions as to how the loss contingency is to be accounted for (i.e., accrual, footnote disclosure or neither accrual not disclosure). SFAS 5 stipulates that a contingent loss must be recognized if it is probable that an asset has been impaired or a liability has been incurred at the date of the financial statements and the amount of the loss can be reasonably estimate. If the loss is deemed to be reasonably possible, disclosure is required but accrual is not needed. No action is required if the occurrence of the contingency is considered remote. Prior research, in general, concludes that individuals often disagree about the exact numeric meaning of the terms probable, reasonable possible and remote, and that there is high between-subject variability when people assign numeric values to the verbal probability expressions in loss contingency literature. IAS 37, Provisions, Contingent Liabilities and Contingent Assets, classifies obligations related to contingencies into two categories: provisions or contingent liabilities. Provisions are obligations that meet the liability recognition criteria and are therefore recognized in the entity's statement of financial position when certain conditions are present including that it "is probable (i.e., more likely than not) that an outflow of resources embodying economic resources will be required to settle the obligation". Those obligations that do not meet the recognition criteria applicable to provisions are classified as contingent liabilities and are disclosed in the notes but never recorded in the accounts.

As mentioned above, ASC 450-20-50 defines "probable" as "the future event or events are likely to occur" [emphasis added] while IAS 37 defines "probable" as "more likely than not" [emphasis added]. Clearly, these two definitions are not the same. A natural question is whether financial statement preparers with a prior understanding of one definition or the other interpret "probable" differently, and whether the judgment differences lead to a different determination of probability. For example, for the same customer contract, will an accountant with a GAAP guidance interpret a higher (or lower) threshold for probability than an accountant with an IFRS guidance? And consequently will an accountant with a GAAP guidance decide that the collectability threshold is met or failed while an accountant with an IFRS guidance may conclude the opposite? We state our hypothesis in the null form as below:

H1: Accountants with GAAP guidance do not judge collectibility threshold differently from those with IFRS guidance.

\section{METHOD}

\subsection{Participants}

The participants are eighty nine upper-level undergraduate students from a large private university. All of the participants are accounting majors and have taken Intermediate Accounting courses. Forty one are male and forty eight female. The subjects volunteered to participate in response to in-class announcements. Demographic information collected at the end of the experiment indicates that $60 \%$ of the students have some work experience, with an average of 2.4 years. All participants have taken at least one statistics class. The experiment was structured as part of a capstone 
accounting course. One of the topics covered extensively in the course is revenue recognition. After briefly summarizing over the new revenue recognition standards referred to above with the class, the instructors ask the students to complete the experimental instrument as topic assessment.

\subsection{Procedure and Task}

We use a one-factor, between-subjects design with repeated measures (five different scenarios) in the experiment. We manipulate the revenue recognition standard at two levels - GAAP and IFRS. All participants are randomly assigned to either the GAAP condition or the IFRS condition, and complete judgments for five different scenarios related to revenue recognition and the "probability" of collectability of consideration. The experiment consists of four steps. First, participants receive the general instructions which introduce the new revenue recognition standard from either a US GAAP or IFRS perspective (the instructions below focus on IFRS 15). See Appendix A.

In step two, we provide the participants in both conditions with the following background information.

"Please help us understand how the term "probable" that is used in ASU 2014-09 regarding the collectability of consideration from the customer should be interpreted. More specifically, in providing guidance with regard to Step 1 mentioned on the previous page (Identify the contract(s) with a customer), paragraph 606-10-25-1 of the Codification states, in part:

"An entity shall account for a contract with a customer that is within the scope of this Topic only when all of the following criteria are met:

e. It is probable that the entity will collect the consideration to which it will be entitled in exchange for the goods or services that will be transferred to the customer. In evaluating whether collectibility of an amount of consideration is probable, an entity shall consider only the customer's ability and intention to pay that amount of consideration when it is due." [emphasis added]

In other words, paragraph 606-10-25-1 cited above indicates that a contract does not exist for purposes of the revenue recognition model (Step 1) unless collectibility of the consideration to which the entity expects to be entitled is probable. This determination is based upon an entity's evaluation of the customer's ability and intention to pay the amount of this consideration when due. Because Step 1 is the gateway to the new revenue recognition model, no revenue can be recognized when an entity concludes that collectibility of consideration is not probable.

Depending on their condition, participants receive either the US GAAP or IFRS definition of the term "probable". Those in the GAAP condition received the following statement:

"Section 450-20-20 of the Codification defines the term "probable" as, "The future event or events are likely to occur".

Those in the IFRS condition receive the statement below:

"Paragraph 37 of IAS 37 defines the term "probable" as, "the event is more likely than not to occur, i.e. the probability that the event will occur is greater that the probability that it will not".

In the third step, the participants receive five short scenarios and answer two questions related to each. The first questions asks, "Do you believe the collectability of the \$_ consideration in this scenario is probable?" The response is a simple "yes" or "no". The second question asks the participants to "assign a percentage estimate $(0 \%$ to $100 \%)$ to the probability of collectability the $\$$ in this scenario." See Appendix B.

In the last portion of the survey, participants answer several demographic questions. The entire experiment took approximately 20 minutes on average to complete. 


\section{RESULTS}

\subsection{Manipulation Check4}

In the post-experimental questionnaire, we asked participants to rate their familiarity with the new revenue recognition standard on an 11 point Likert scale ( 1 being very unlikely and 11 being very likely). The average rating is 5.37 . The means for the two conditions are not statistically different.

\subsection{Test of Hypothesis}

In the first question for each scenario, we ask participants to decide whether they believe the collectability of the consideration in this scenario is probable. Table one shows tabulations of "yes" and "no" responses. We find that the participants are largely consistent in their choices in scenario one, four and five. For scenario one, all participants in both conditions believe that collectibility is probable. In both conditions, the majority answered "yes" for scenario five and "no" for scenario four. But the pattern become less clear in the other two scenarios. In scenario two, in the GAAP condition, the majority choose "no", but in the IFRS condition, the answers are equally split. However, Chisquare tests indicate that none of the differences is significant. Therefore, we can conclude that the pattern of choices do not differ across the two conditions.

The second question asks participants to assign a percentage estimate ( $0 \%$ to $100 \%)$ to the probability of collectability in each scenario. To test hypothesis one, we performed a one way ANOVA with repeated measures, where the five scenarios is the within-subjects variable, the standard (GAAP vs. IFRS), the between-subjects variable. Multivariate tests indicate that Wilks lambda for the within-subjects variable of different scenarios has a value of 0.09 ( $F=197.83$, $\mathrm{p}<0.05)$ and is significant, indicating the percentage judgments for the five different scenarios are significantly different from each other. The Wilks lambda $(0.96, \mathrm{f}=0.80, \mathrm{p}>0.05)$ is nonsignificant for the interaction between scenario and condition. This suggests that participants' judgments do not differ across different GAAP or IFRS. We further examine the Mauchly's Test of Sphericity and find that the value of 0.62 with 9 degrees of freedom is significant $(\mathrm{p}=0.00)$. The significant $\mathrm{p}$ value suggests that the assumption of sphericity was not met. Unfortunately, this means that we cannot rely on the multivariate tests examined above. Thus, we use a repeated measures ANOVA with a Greenhouse-Geisser correction to determine the mean difference. The test shows a significant within-subjects effect for scenarios $(\mathrm{p}<0.00)$ but a nonsignificant effect of scenario and standard $(\mathrm{p}>0.00)$.

Apparently, the percentage estimate of probability of collectability of consideration assigned by participants are quite high in scenarios one and five and lowest in scenario four. See table two for means and t tests. Percentage judgement falls in between $47 \%$ and $56 \%$ for scenarios two and three. The significant within-subjects factor of scenario is consistent with our intention as we selected scenarios varying in their uncertainty. By employing five different scenarios we intended to elicit judgments across different spectrums. However, we did not find any significant effect on the between-subjects factor as percentages assigned by participants are very similar across each scenario. This suggests that participants do not interpret the term "probable" differently across the GAAP or IFRS condition, and thus, we are not able to reject our null hypothesis.

\subsection{Post-Test}

One week after the experiment, we ask the same participants to answer one additional question about their probability judgments. We separate the participants into three groups, GAAP, IFRS or Both. In the GAAP group, participants receive the following information:

Section 450-20-20 of the US Codification defines the term "probable" as, "The future event or events are likely to occur".

In the IFRS group, participants receive the following information: 
Paragraph 37 of IAS 37 defines the term "probable" as, "the event is more likely than not to occur, i.e. the probability that the event will occur is greater that the probability that it will not".

The last group of participants receive both statements.

Then participants are asked the following question:

We would like to know your interpretation of the term "probable”. Please assign a percentage estimate $(0 \%$ to $100 \%$ ) to the term "probable".

Your percentage estimate is $\%$

The following table shows the descriptive statistics for the above question. It appears that participants assigned the highest percentage estimate for the term "probable" in the GAAP condition but the one way ANOVA shows the difference is not statistically different as their means are not significantly different from each other $(\mathrm{F}(2,88)=1.57$, $\mathrm{p}=0.21$ ) in the three conditions. Post hoc tests indicate none of the multiple comparisons is significant either.

Table 1. Frequency of "Yes" and "No" Responses to Collectibilty

\begin{tabular}{c|c|c|c|c}
\hline Scenario & & Yes & No & \\
\hline \multirow{2}{*}{ One } & GAAP & 44 & 0 & $\mathrm{n}=44$ \\
& IFRS & 45 & 0 & $\mathrm{n}=45$ \\
\hline \multirow{2}{*}{ Two } & GAAP & 19 & 25 & $\mathrm{n}=44$ \\
& IFRS & 25 & 25 & $\mathrm{n}=45$ \\
\hline \multirow{2}{*}{ Three } & GAAP & 23 & 21 & $\mathrm{n}=44$ \\
& IFRS & 20 & 25 & $\mathrm{n}=45$ \\
\hline \multirow{2}{*}{ Four } & GAAP & 5 & 39 & $\mathrm{n}=44$ \\
\hline \multirow{2}{*}{ Five } & IFRS & 2 & 43 & $\mathrm{n}=45$ \\
\hline & GAAP & 41 & 3 & $\mathrm{n}=44$ \\
\hline
\end{tabular}

Table 2. Probability Judgments across Five Different Scenarios

\begin{tabular}{|c|c|c|c|c|c|c|}
\hline Scenario & & Mean & Std. & $\mathbf{t}$ & sig & n \\
\hline \multirow{2}{*}{1} & GAAP & $93 \%$ & 6.19 & \multirow[t]{2}{*}{0.95} & \multirow[t]{2}{*}{0.35} & 44 \\
\hline & IFRS & $91 \%$ & 11.03 & & & 45 \\
\hline \multirow{2}{*}{2} & GAAP & $47 \%$ & 21.39 & \multirow[t]{2}{*}{-0.96} & \multirow[t]{2}{*}{0.34} & 44 \\
\hline & IFRS & $52 \%$ & 22.21 & & & 45 \\
\hline \multirow{2}{*}{3} & GAAP & $54 \%$ & 19.87 & \multirow[t]{2}{*}{-0.35} & \multirow[t]{2}{*}{0.73} & 44 \\
\hline & IFRS & $56 \%$ & 21.63 & & & 45 \\
\hline \multirow{2}{*}{4} & GAAP & $20 \%$ & 23.07 & \multirow[t]{2}{*}{0.48} & \multirow[t]{2}{*}{0.64} & 44 \\
\hline & IFRS & $18 \%$ & 24.54 & & & 45 \\
\hline \multirow{2}{*}{5} & GAAP & $73 \%$ & 14.72 & \multirow[t]{2}{*}{0.76} & \multirow[t]{2}{*}{0.45} & 44 \\
\hline & IFRS & $70 \%$ & 18.89 & & & 45 \\
\hline
\end{tabular}

Table 3. Post-Test Results for Probability Judgments for "Probable"

\begin{tabular}{l|c|c|c|c|c}
\hline & n & Mean & std & min & max \\
\hline GAAP & 33 & 72.52 & 11.71 & 50 & 100 \\
\hline IFRS & 30 & 68.50 & 12.44 & 50 & 90 \\
\hline Both & 28 & 67.25 & 12.65 & 50 & 100 \\
\hline Total & 91 & 69.57 & 12.32 & 50 & 100 \\
\hline
\end{tabular}




\section{CONCLUSION}

In this study, we attempt to better understand whether the different definitions of "probable" provided by GAAP and IFRS may lead to differences in applying the fully converged revenue recognition standard. The results of our experiment illustrate that the differing definitions of "probable" do not lead to do not lead to differences in the application of the new converged revenue standard. Our experiment indicates that revenue would be recognized in the same manner under both GAAP and IFRS. This is supported in our post-test, where we find that participants interpret the definitions of "probable" in a similar fashion under GAAP and IFRS, as the numeric percentages they assigned to "likely" (GAAP) or "more likely than not" (IFRS) are not significantly different. Our results suggest that the financial statement preparers will evaluate the collectability threshold in a consistent manner whether it be implemented under GAAP or IFRS. Accordingly revenue will be recognized in a consistent manner across all entities.

\section{AUTHOR BIOGRAPHY}

Ning Du is an associate professor with School of Accountancy and MIS, DePaul University. She received her Ph.D. from University of Illinois at Urbana-Champaign. Her research bridges the gap between psychology and accounting with a special focus on judgment and decision making for financial information users. She has published many articles in various journals such as Management Science, Organizational Behavior and Human Decision Processes, Journal of Behavioral Finance, Accounting Research Journal, International Journal of Forecasting, The CPA Journal, Research in Accounting Regulations, and Managerial Auditing.

Professor R. Mark Alford is a Senior Professional Lecturer at DePaul University in Chicago, Illinois. He teaches primarily in the areas of financial accounting (the capstone course in both the undergraduate and Master of Science in Accountancy programs) and managerial accounting. Dr. Alford has published numerous articles including papers in Accounting Horizons, Issues in Accounting Education and The CPA Journal. Dr. Alford has previously held faculty positions at the University of Houston and the University of Texas at San Antonio.

Professor Patricia L. Smith is a Professional Lecturer at DePaul University in Chicago, Illinois. She teaches primarily in the area of financial accounting (introductory, intermediate and the capstone course in the undergraduate program). Ms. Smith has presented at the annual AAA conference as well as at several regional conferences.

\section{REFERENCES}

Amer, T. S., K. Hackenbrack, and M. W. Nelson.1994. Between-auditor differences in the interpretation of probability phrases. Auditing: A Journal of Practice \& Theory, 126-136.

Amer, T. S., K. Hackenbrack, and M. W. Nelson.1995. Context-dependence of auditors' interpretations of the SFAS No. 5 probability expressions. Contemporary Accounting Research, 2 (1), 25-39.

Beyth-Marom, R. (1982). How probable is probable? A numerical translation of verbal probability expressions. Journal of Forecasting, 1, 257-269.

Bonner, S. E. and Walker, P. L. 1994. The Effects of Instruction and Experience on the Acquisition of Auditing Knowledge. The Accounting Review, 69 (1), 157-178.

Budescu, D.V., and Wallsten, T.S.1995. Processing linguistic probabilities: General principles and empirical evidence. In J.R. Busemeyer, R. Hastie, \& D. Medin (Eds.), The psychology of learning and motivation: Decision making from the perspective ofcognitive psychology (pp. 275-318). New York: Academic Press.

Budescu, D.V., S. B. Broomell, and P. Han-Hui (2009). Improving Communication ofUncertainty in the Reports of the Intergovernmental Panel on Climate Change. Psychological Science, in press.

Chesley, G. R. 1986. Interpretations of uncertainty expressions. Contemporary Accounting Research, 179-99

Doupnik, T. S., and M. Richter. (2003). Interpretation of Uncertainty Expressions: A CrossNational Study. Accounting, Organizations and Society, 28 (1): 15-35.

Doupnik, T. S., and M. Richter. (2004). The Impact of Culture on the Interpretation of "I Context" Verbal Probability Expressions. Journal of International Accounting Research, 3 (1): 1-20. Du, N., K. Stevens., and J. McEnroe. 2011 a. Improving Consistency in Interpreting SFAS 5. Research in Accounting Regulation 23(1), 67-70

Du, N., K. Stevens., and J. McEnroe. 2011b. Numeric to Verbal Translation of Probability Expressions in SFAS 5. Managerial Auditing, 26(3), 248-262 
Du, N., K. Stevens, Ahern, John and Shigaev, Anton. 2016. Cross-cultural Differences in Interpreting IAS 37 Probability Phrases 7(1) Financial Accounting Standards Board. 1975. Accounting for Contingencies, Statement of Financial Accounting Standards No. 5 (Stamford, Conn.: FASB). http://www.fasb.org/home

Gary, S. J. 1988. Towards a Theory of Cultural Influence on the Development of Accounting Systems Internationally. Abcus. 24 (1): $1-15$.

Harrison, K.E., and L.A. Tomassini. 1989. Judging the probability of a contingent loss: an empirical study. Contemporary Accounting Research, 642-648.

International Accounting Standard Committee, 1998. Provisions, Contingent Liabilities and Contingent Assets. International Accounting Standard No. 37, London, UK. http://www.ifrs.org/Pages/default.aspx

Jiambalvo, J., and N. Wilner. 1985. Auditor evaluation of contingent claims. Auditing: A Journal of Practice and Theory, 1-11.

Liby R., and J. Luft. 1993. Determinants of Judgment Performance in Accounting Settings:Ability, Knowledge, Motivation and Environment, Accounting, Organization and Society. 18(5), 425-450.

Raghunandan, K., R.A. Grimlund, and A. Schepanski. 1991. Auditor evaluation of loss contingencies. Contemporary Accounting Research, 549-569

Reimers, J. L. 1992. Additional evidence on the need for disclosure reform. Accounting Horizons. 36-41.

Wallsten, T. S., D. V. Budescu, D. V., R. Zwick, R., and S. M. Kemp. 1993. Preferences and reasons for communicating probabilistic information in numerical verbal terms. Bulletin of the Psychonomic Society, 31, 135-138.

Wallsten, T. S., S. Fillenbaum, and J. A. Cox. 1986. Base rate effects on the interpretations of probability and frequency expressions. Journal of Memory \& Language, 25, 571-587. 


\section{APPENDIX A}

\section{GENERAL INSTRUCTIONS}

Thank you for agreeing to participate in this study. In May 2014 the FASB and IASB issued their long-awaited converged standards on revenue recognition. Accounting Standards Update (ASU) 2014-09 (the effective date for ASU 2014-09 was postponed for one year with the issuance of ASU 2015-14) was issued by the FASB. According to ASU 2014-09 (Topic 606 in the FASB Accounting Standards Codification), "The core principle of the guidance is that an entity shall recognize revenue to depict the transfer of promised goods or services to customers in an amount that reflects the consideration to which the entity expects to be entitled in exchange for those goods or services." Continuing, "An entity recognizes revenue in accordance with that core principle by applying the following steps:

Step 1: Identify the contract(s) with a customer.

Step 2: Identify the performance obligations in the contract.

Step 3: Determine the transaction price.

Step 4: Allocate the transaction price to the performance obligations in the contract.

Step 5: Recognize revenue when (or as) the entity satisfies a performance obligation."

The purpose of this research project that you are being asked to participate in is to better understand how accounting practitioners may interpret certain terminology embedded in the new U.S. GAAP standard. You should be able to complete the attached survey in about 20 minutes.

The attached materials contain two short tasks. In the first task, you will be asked to interpret the use of the term "probable" as it is used in the authoritative guidance related to Step 1 above and then apply your interpretation to several scenarios. In addition, you will be asked a series of questions about you and your background and work experience. Your responses will remain strictly confidential and will be analyzed only after being combined with the responses of other participants.

You may now proceed with the case. Thank you again for participating in the study. 


\section{APPENDIX B}

\section{Scenario One:}

RoBo Company manufactures construction-related machinery including front-end loaders. On March 2, 20X5, RoBo contracts with one of its customers, Abby, Inc., for the purchase of three of the loaders for $\$ 20,000$ each ( $\$ 60,000$ total) to be delivered on June 30,20X5. Payment is due by December 31, 20X5. Abby has made purchases of machinery from RoBo on several previous occasions and has always paid for the purchases in full and on time. Assume that delivery of the front-end loaders occurred as scheduled on June 30, 20X5 and at that time RoBo has no further performance obligations.

\section{Scenario Two:}

Turner, Inc. is a real estate developer. Turner recently entered into a contract with its customer, Horizon Properties, for the sale of a building for $\$ 1,000,000$ on January 4, 20X5. Horizon intends to open a high-end grocery store in the building. The area around the building that Horizon purchases already has a number of highend grocery store and new stores will face fierce competition. Horizon has little experience in the grocery business.

\section{Scenario Three:}

Franco's Boxing Club enters into a one-year membership contract with an aspiring boxer, Pedro Fuentes, on November 1, 20X5. The contract stipulates that $\$ 100$ is due on the date the contract. Pedro pays the initial $\$ 100$. Franco's checks the credit rating of all of its customers and discovers that Pedro has a poor credit score.

\section{Scenario Four:}

Princeton Furniture agrees to sell $\$ 100,000$ worth of furniture to the developer of a new office complex, Office Innovators, on August 11, 20X5. Princeton discovers that Office Innovators has a favorable credit rating. The furniture is delivered on August 31,20X5 and payment is due by November 30, 20X5. A fire breaks out in the new office complex on September 20,20X5 and all of the furniture purchased from Princeton is destroyed. As a result of the fire, Office Innovators suffered significant uninsured losses and filed for bankruptcy on November $19,20 \times 5$.

\section{Scenario Five:}

Moore \& Co. sells household appliances to retailers. All payments for purchases are due 30 days from the purchase date. Moore sells Custom Appliances $\$ 250,000$ in assorted appliances on May 11, 20X5. Custom Appliances has an average credit rating. 


\section{NOTES}

